Article

\title{
Construction Hazard Investigation Leveraging Object Anatomization on an Augmented Photoreality Platform
}

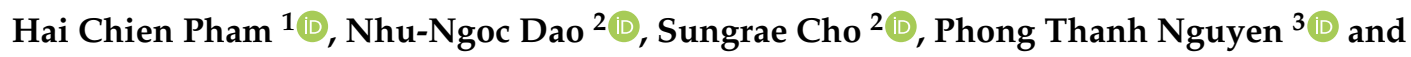 \\ Anh-Tuan Pham-Hang $4, *$ (D) \\ 1 Applied Computational Civil and Structural Engineering Research Group, Faculty of Civil Engineering, \\ Ton Duc Thang University, Ho Chi Minh City 7000000, Vietnam; phamhaichien@tdtu.edu.vn \\ 2 School of Computer Science and Engineering, Chung-Ang University, Seoul 06974, Korea; \\ dnngoc@uclab.re.kr (N.-N.D.); srcho@cau.ac.kr (S.C.) \\ 3 Department of Project Management, Ho Chi Minh City Open University, Ho Chi Minh City 7000000, \\ Vietnam; phong.nt@ou.edu.vn \\ 4 School of Computer Science and Engineering, International University-Vietnam National University \\ HCMC, Block 6, Ward Linh Trung, Thu Duc District, Ho Chi Minh City 7000000, Vietnam \\ * Correspondence: anhtuanphamhang@gmail.com; Tel.: +84-902437625
}

Received: 26 September 2019; Accepted: 18 October 2019; Published: 23 October 2019

\begin{abstract}
Hazard investigation education plays a crucial role in equipping students with adequate knowledge and skills to avoid or eliminate construction hazards at workplaces. With the emergence of various visualization technologies, virtual photoreality as well as $3 \mathrm{D}$ virtual reality have been adopted and proved advantageous to various educational disciplines. Despite the significant benefits of providing an engaging and immersive learning environment to promote construction education, recent research has also pointed out that virtual photoreality lacks a 3D object anatomization tools to support learning, while 3D-virtual reality cannot provide a real-world environment. In recent years, research efforts have studied virtual reality applications separately, and there is a lack of research integrating these technologies to overcome limitations and maximize advantages for enhancing learning outcomes. In this regard, the paper develops a construction hazard investigation system leveraging object anatomization on an Interactive Augmented Photoreality platform (iAPR). The proposed iAPR system integrates virtual photoreality with 3D-virtual reality. The iAPR consists of three key learning modules, namely Hazard Understanding Module (HUM), Hazard Recognition Module (HRM), and Safety Performance Module (SPM), which adopt the revised Bloom's taxonomy theory. A prototype is developed and evaluated objectively through interactive system trials with educators, construction professionals, and learners. The findings demonstrate that the iAPR platform has significant pedagogic methods to improve learner's construction hazard investigation knowledge and skills, which improve safety performance.
\end{abstract}

Keywords: construction hazard; safety education; photoreality; virtual reality; anatomization

\section{Introduction}

The construction industry has been recognized as a dangerous and hazardous industry throughout the world [1,2]. Despite providing a significant contribution to a country's development, construction accidents have accounted for a very high rate among various industries [3]. For instance, safety statistics reveal that construction accounts for 20-40 percent of the occupational fatal accidents in spite of employing just around 6-10 percent of the workforce. Throughout the world, approximately 60,000 construction fatalities occur per year, which corresponds to one injury every nine minutes [4]. 
Consequently, fatalities and injuries cause many cost overruns and delays, which negatively impact the project safety performance [5]. To reduce construction accidents at the workplace, it is very important to provide graduates with hazard education at the tertiary level, so that they have professional hazard knowledge and skills [6,7].

In the past decades, virtual reality has been acknowledged as a state-of-the-art technology to improve hazard education [8]. The 3D CAD models are developed using computer to provide a 3D virtual reality (3D-VR) platform [9]. The advantage of 3D-VR is that it provides virtual construction sites, where students can interact with the educator and other learners to obtain hazard knowledge and skills [10]. With an interactive learning environment, learners will be motivated and engage sufficiently with their construction hazard investigation and recognition [11]. Moreover, recent efforts [12] have developed 3D-VR based object anatomization models for anatomizing and analyzing complicated hazard case studies. This object anatomization approach has benefits not only in construction hazard education [12] but also in other disciplines [13-15]. Despite its advantages, 3D-VR lacks a real-word environment [16], in which graduates can experience practical construction sites to investigate hazards.

To improve the real-world experience, 360 degree panoramic Virtual Photoreality (360VP) has emerged as a potential pedagogic tool for learners to experience real-word construction workplace environments [17]. The advantage of 360VP is that it provides an immersive learning platform, where the learner can move flexibly and observe the scenes to investigate hazards as they would experience in real construction sites [18]. Due to the greater immersion and higher degree of realism, 360VP assists learners in experiencing an emotional and cognitive presence at the scene. Moreover, the 360VP platform has been proved to be energy-efficient [19] and cost-efficient compared to the 3D-VR [20]. Despite the prominent advantages, the current applications of 360VP still lack 3D object anatomization tool to enhance the learning outcomes. Moreover, in recent years, researchers have focused on adapting virtual reality technologies separately, and lack of research integrates 360VP with 3D-VR to eliminate limitations and maximize the advantages of these technologies for promoting educational purposes.

In response to this status-quo, this research proposes a construction hazard investigation system, which leverages 3D object anatomization on an Interactive Augmented Photoreality (iAPR) platform. The proposed iAPR system augments a 360VP platform by integrating 3D-VR object anatomization technologies in order to create a learning environment, which reflects a real-word construction workplace. The iAPR consists of three key learning modules including Hazard Understanding Module (HUM), Hazard Recognition Module (HRM), and Safety Performance Module (SPM), which adapt Bloom's taxonomy learning theory for hazard investigation knowledge and skill development of learners. A prototype is developed with hazard cases that often occur in real construction workplaces. In addition, the effectiveness of iAPR in improving the hazard investigation is validated using before-after experimental studies. Due to the prominent visibility characteristic of 360VP and 3D-VR technologies using in the iAPR system, learners can only investigate the construction hazards through "sight" sense. Thus, recognizing and evaluating hazards, which need to use other human senses such as smell, touch, hearing, are out of research scope.

\section{Related Work}

\subsection{Bloom's Taxonomy for Construction Hazard Education}

Bloom's cognitive taxonomy was an attempt to improve educational objectives regarding assessment and testing of teaching materials [21]. It provided an organizational structure including six categories, namely knowledge, comprehension, application, analysis, synthesis and evaluation, which are arranged from the simplest to the most complex. Subsequently, many theorists have developed improvements in the domains of human learning such as effective domain [22] and psychomotor domain [23-25]. In 2001, Anderson and Krathwohl [26] proposed a revised Bloom's taxonomy which improved from uni-dimension to two-dimension. In the knowledge dimension, the authors classified four types: factual, conceptual, procedural, and metacognitive knowledge. In the cognitive process 
dimension, six levels were changed into verb format: 1-remembering, 2-understanding, 3-applying, 4-analyzing, 5-evaluating, and 6-creating [21]. With the combination of two dimensions, educators could change from passive views of learning towards active engagement in meaningful learning [26]. Bloom's taxonomy and its revised version became the standard for designing educational curricula [27]. For example, Thambyah et al. [28] recommended twenty four learning outcomes based on the revised Bloom's taxonomy for the final year project of undergraduate engineering. In addition, it provided for teachers a common language to compare and discuss between two different subject areas, understand how these subjects overlap, and deliver the conceptual and practical knowledge concurrently [29]. Thus, Bloom's taxonomy could widely influence the educational systems as a whole, through teacher preparing programs, assessment programs, and educational research [30]. A survey of the education literature also revealed that several studies attempted to apply and implement the taxonomy in many domains of education including computing, medical and nursing, music, and engineering [31].

In the construction hazard domain, there is a potential to apply Bloom's taxonomy for educational enhancement. The recent assessment methods reveal a gap in evaluating the implementation level of safety knowledge and skills in practice [32]. To overcome these gaps, appropriate approaches and solutions based on cognitive and awareness processes should be proposed to achieve the learning outcomes and maximize the collective amount of knowledge for each objective. Using Bloom's taxonomy, Kaskutas et al. [33] identified the gap between fall prevention training and the favorite learning methods of apprentices, and then designed new curricula. Endroyoa et al. [34] built an occupational safety and health model to achieve learning outcomes according to Bloom's taxonomy. Pedro et al. [35] proposed a context-based assessment system to improve visualization in teaching safety knowledge. Moreover, there is a growing tendency to apply modern technologies to construction hazard education. Building anatomy modelling [36] and social virtual reality integrated into construction safety system [5] are some examples. Although most studies have their own evaluation system, the application of Bloom's taxonomy could be beneficial in helping educational programs better meet their learning objectives.

\subsection{Virtual Reality in Construction Hazard Investigation}

Virtual Reality (VR) has been applied widely in the context of hazard education and training in recent years [37]. Several VR applications have been developed for hazard identification for targeted users such as designers, site workers, construction students, safety managers, among others. For example, these research efforts include Design-for-Safety-Process (DFSP) systems [38], Cave Automatic Virtual Environments (CAVEs) [39], System for Augmented Virtuality Environments (SAVEs) [40], Visualized Safety Management System (VSMS) [1], Multiuser Virtual Safety Training System (MVSTS) [41], among others. Le et al. developed a learning framework based on an online social VR system, which includes role-playing, dialogic learning, and social interaction for construction safety and health education [5]. Following this, researches have proved the advantages of VR in providing interactive and experiential learning environments [42,43], which are very important to motivate and engage learners in obtaining hazard knowledge and skills [44]. In an effort to develop VR systems that can provide close-to-reality visibility, recent studies have adopted the 360VP technology, which captures 360 panorama images of real construction sites [17]. The 360VP enhances the real-world learning environment by presenting the dynamic nature of construction sites in reality to improve the hazard investigation knowledge skills of construction students and professionals. Furthermore, 360VP has demonstrated improvements in not only hazard education and training [45], but also energy-efficiency [19]. Since VR or 360VP have their own limitations, researches have tried to integrate some VR technologies in order to enhance the advantages of these VR technologies so that hazard education and training can be improved. 


\section{Framework}

The iAPR learning framework consists of three modules including Hazard Understanding Module (HUM), Hazard Recognition Module (HRM), and Safety Performance Module (SPM) in order to improve the construction hazard investigation knowledge and skills of learners (see Figure 1). These modules adopt six Bloom's levels of critical thinking development through the iAPR platform.

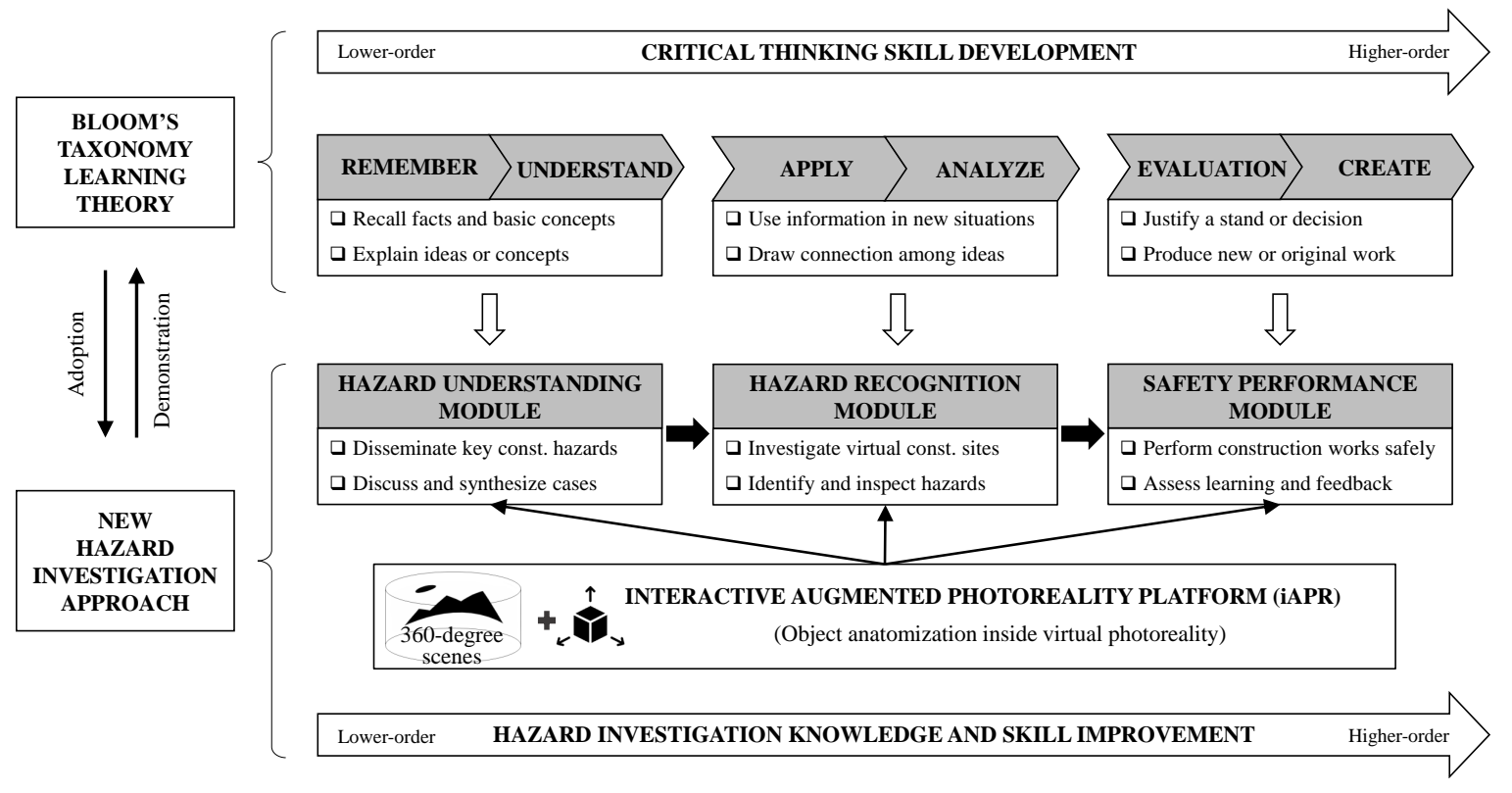

Figure 1. Learning framework.

In particular, HUM aims to help learners remember and understand hazards that often happen in real construction sites. To do this, the educator disseminates key construction hazards in HUM. Following educator instruction, the learners participate in an online discussion to discuss and analyze the hazard cases provided by the educators. During discussion, the learners can easily ask questions to the educator as well as other learners through the chatroom (see Figure 2a) in the iAPR platform. Moreover, hazard-related e-materials (object anatomization, links to images, videos, animation, and e-documents) are supported and can be uploaded through the chatroom in order to provide comprehensive information of the hazard case being discussed. The educator explains the contents in detail, and then synthesizes each hazard case to ensure that all learners thoroughly understand the lesson and hazard-related issues before moving to the next step. As depicted in Figure 1, HUM applies the first two levels of Bloom's taxonomy learning theory for construction hazard education.

Next, HRM focuses on assisting learners to apply the hazard knowledge they learned in the HUM in order to recognize new hazards. To do this, HRM provides an iAPR platform where learners experience virtual construction sites to inspect hazards. In particular, the learners play the role of a safety manager to investigate potential hazards, which are embedded by hotspots (see Figure 2b) in the virtual jobsite. Each hotspot includes hazard information and e-materials related to hazardous scenarios in order to help the learners recognize potential hazards. During hazard investigation in the $\mathrm{iAPR}$ environment, the online chatroom assists learners establish online meetings to discuss and share e-materials with other learners when analyzing difficult hazardous situations. This illustrates a common approach that a safety manager needs to adopt in reality when facing difficult problems during construction. While inspecting the recognized hazard, the learners are required to address the root causes, and then propose prevention methods for eliminating the hazard. Furthermore, by clicking on an anatomy function (the second function from the right in the hotspot), a 3D anatomy popup window (see on the right of Figure $2 \mathrm{~b}$ ) appears, assisting learners to perform prevention methods by anatomizing 3D objects (scaffolding, working platform, temporary safety handrails, 
mobile ladders, safety barriers, etc.). For example, if a construction hazard arises due to improper erection or dismantling of scaffolding, the learners are required to perform proper scaffolding erection and dismantling for ensuring safety. After finishing a hazard inspection, the learners are required to investigate other hazardous scenarios in the virtual panoramic construction site by themselves in order to consolidate their hazard knowledge. HRM adopts two application and analysis levels of Bloom theory for improving the hazard investigation and recognition skills of learners.

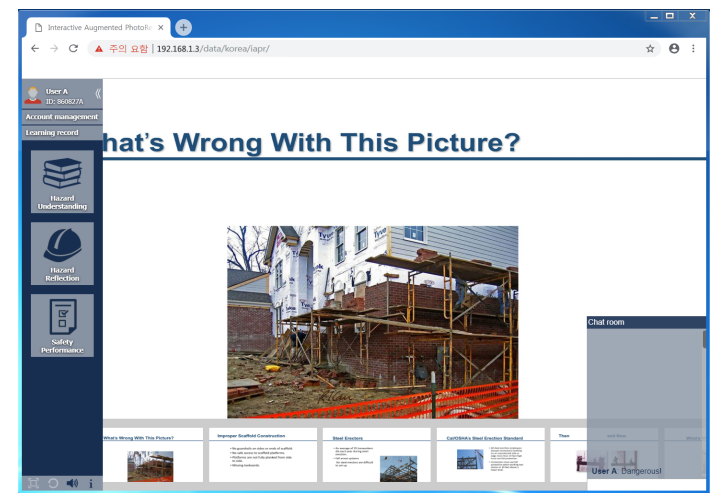

(a) Hazard Understanding Module (HUM)

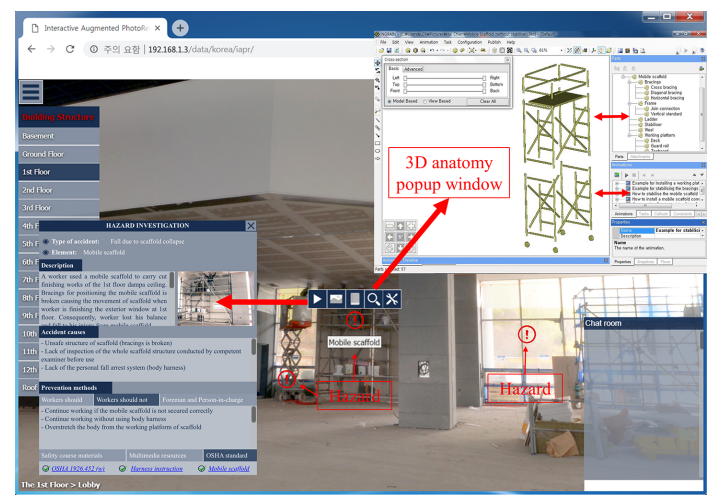

(b) Hazard Recognition Module (HRM)

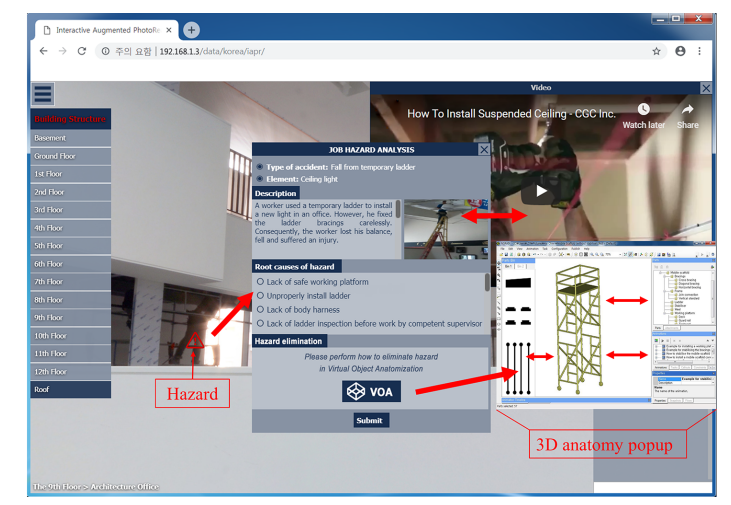

(c) Safety Performance Module (SPM)

Figure 2. The Interactive Augmented Photoreality platform (iAPR) prototype interfaces.

Finally, the purpose of SPM is to evaluate the hazard investigation knowledge and skills that learners obtained from the previous modules. To do this, the learners are required to finish a game-based testing on the iAPR platform (see Figure 2c). Through an individual account, each learner acts as a safety manager to navigate a virtual construction site for analyzing dangerous situations. After accurately identifying a potential hazard that is embedded by a alarm sign, a popup window appear, showing a Job Hazard Analysis (JHA) report. The learner has to answer all questions in the JHA, including accident type, hazard description, root causes, as well as prevention methods to eliminate the hazard. Especially, a 3D anatomy popup window (see on the right of Figure 2c) would appear when the user clicks on the Virtual Object Anatomization (VOA) function in the JHA. This function assists the learner to easily propose prevention methods by anatomizing $3 \mathrm{D}$ objects such as mobile scaffold, guardrails, etc. For example, as illustrated in Figure 2c, learners are required to install a mobile scaffold step by step in order to prevent a fall from temporary ladder in this recognized dangerous case. Through this, learners can improve their hazard elimination skills. After that, they continue to investigate other potential hazards. Due to the significant importance of hazard investigation skills for preventing construction accidents in practice, the learners cannot move to the next step if they have not accurately investigated and inspected all the hazards in the current step. The iAPR system automatically records the game-based testing performance and feedback of learners for assessing their 
hazard investigation knowledge and skills. As shown in Figure 1, SPM demonstrates the adoption of the last two Bloom's levels for educating construction hazards.

\section{System Architecture}

From a systematical perspective, the iAPR architecture is designed by adopting a standard web-app model including three major components: iAPR browser-based client, web service server, and central database; see Figure 3. In the iAPR system architecture, the server and database are implemented in data center on the cloud, while the client is locally installed on user devices. Accordingly, the connection between the server and database is internal. Meanwhile, the client and server communicate with each other via an external networking infrastructure (e.g., Internet).

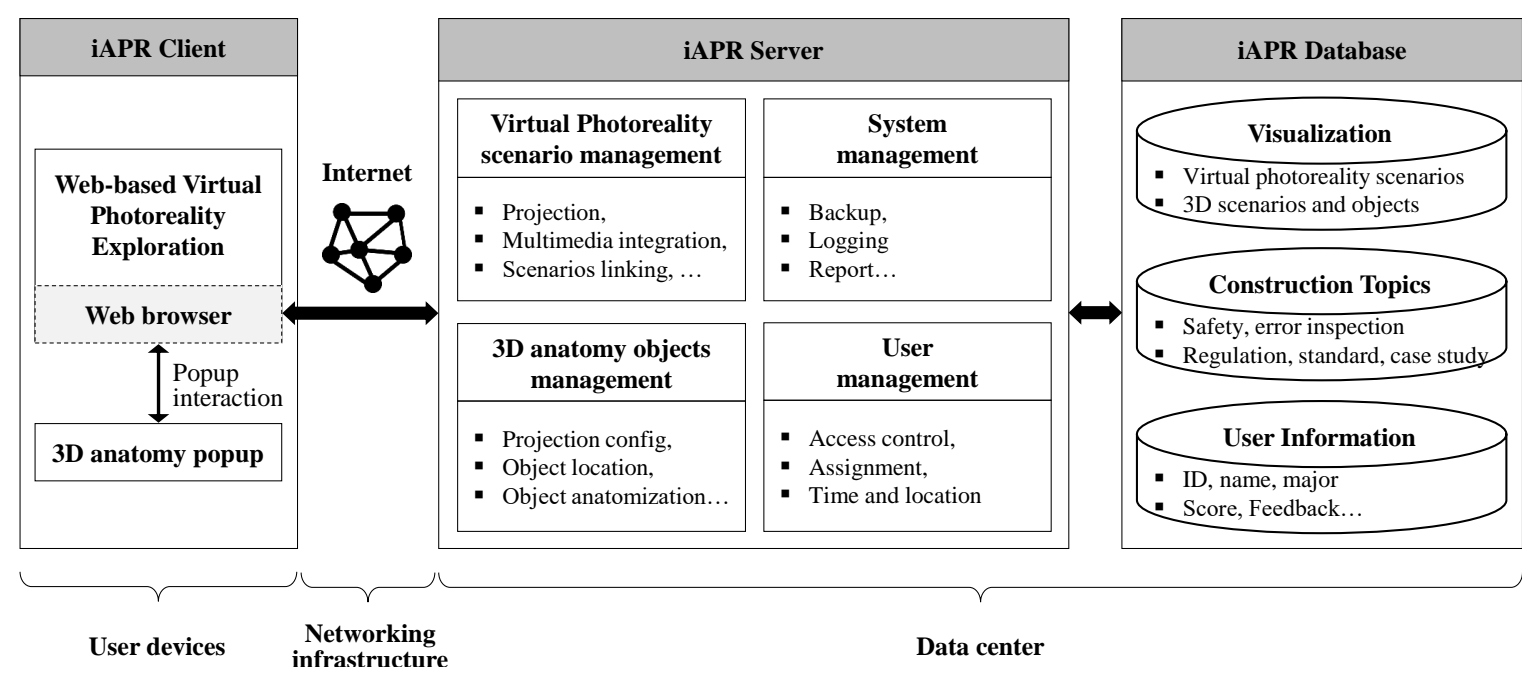

Figure 3. System architecture.

In the iAPR system, the web service server plays a key role and performs four core functions, namely virtual photoreality scenario, 3D anatomy of objects, system management, and user management. In particular, the VP scenario management function provides digital image rendering and projection to reconstruct the captured real environment on the screen. By using multiple deterministic anchors on the surface of the projected sphere, multimedia contents and inter-scene linking objects can be integrated to generate an interactive environment for human sightseeing behavior. On the other hand, the 3D anatomy object management function enables users to perform object projection configuration, multi-level anatomization, and integration on the VP scenario. By default, these functions are activated by user requests through interaction with the corresponding objects inside the VP scenes. In addition, typical system and user management functions are developed to monitor the system operations (e.g., backup, logging, and reporting) and user access (e.g., access control, role assignment, and time\&date and location), respectively.

On the iAPR database server side, three databases are designed to manage visualization, construction topics, and user information data. Among these databases, the visualization volume contains VP scenarios, multimedia contents, and 3D object components. The construction topics volume stores the learning data such as safety, error inspection, construction regulation, standard, and case studies. Lastly, the user information volume manages user ID, name, education major, subject score and feedback, etc.

These iAPR servers are located on the cloud to ensure high service availability, and they are accessed from user devices through a networking infrastructure [46]. It is worth noting that the web-based application is designed to work on the Internet protocol (IP) stack; therefore, the iAPR system is able to adapt to almost all popular networking technologies such as cellular and WiFi access networks $[47,48]$. In the user devices, the iAPR client mainly operates using the built-in web browser to access the iAPR system. When a VP scene is loaded, its integrated 3D objects are temporally cached 
on the dedicated memory. The 3D objects are called by using popup interaction in the web browser to initiate a 3D anatomy window.

The iAPR system architecture design is advantageous from several perspectives as follows:

- The adoption of Web-app model allows the iAPR application to provide services to a variety of user device classes regardless of their current operation systems (iOS, Android, Windows, and Linux) and processing capability.

- The Central server deployment and module-based function development enables easy maintenance and upgrade of system functions and contents.

- The IP-based service implementation facilitates either local or remote user access technologies via heterogeneous networking infrastructures.

\section{System Evaluation}

\subsection{Prototype Development}

In order to evaluate the advantages of the proposed iAPR system, a prototype of the iAPR was implemented by adopting the above-mentioned system evaluation scheme. In particular, the iAPR server was developed by utilizing the Krpano 1.19 framework [49], which provides stable and open interfaces for VP applications. Krpano 1.19 is certified to adapt to the latest version of webvr engine in various web browsers. Moreover, the Krpano enables advanced web-app programming languages such as Hypertext Markup Language version 5 (HTML5), Cascading Style Sheets version 3 (CSS3), eXtensible Markup Language (XML), and JavaScript. On the other hand, mySQL server [50] is used for iAPR database management. The iAPR system was installed on a Raspberry Pi Model B [51] equipped with a 64GB SD card. The Raspberry Pi server connects to a WiFi access point, which provides both local and Internet access for user devices; see Figure 4. In the user devices, the iAPR client consists of a built-in web browser for permanent 360VP scenario access and an NGRAIN interface [52] for 3D anatomy popup window per user demands. The iAPR client is installed on Windows OS. Technical details of the iAPR system setup are summarized in Table 1. For VP data preparation, Samsung Gear 360 camera [53] is used to capture real scenes from construction sites while multimedia videos are uploaded to either an authorized YouTube channel or a local server to get their links.

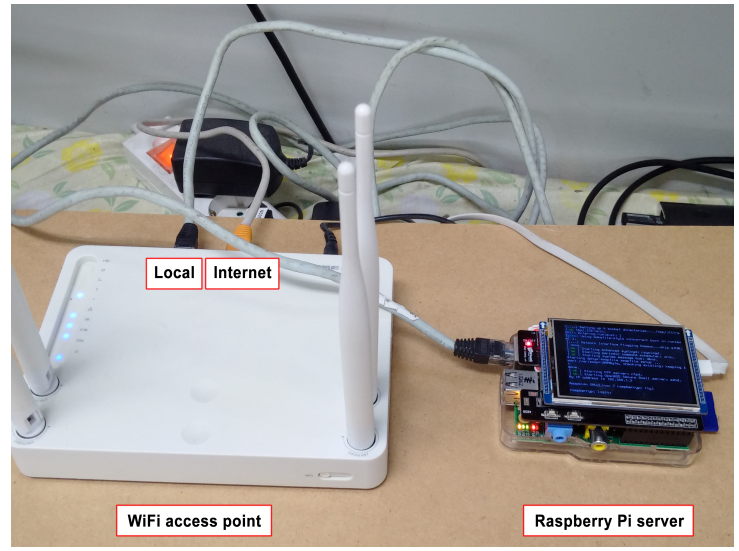

(a) iAPR server

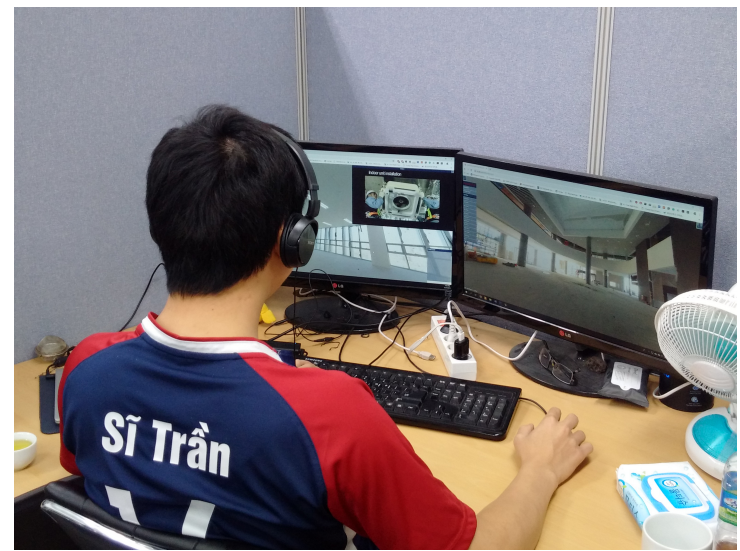

(b) iAPR client

Figure 4. The iAPR system prototype implementation. 
Table 1. System prototype configuration.

\begin{tabular}{ccc}
\hline & iAPR Server & iAPR Client \\
\hline Hardware & Raspberry Pi Model B & Laptops and PCs \\
OS & Linux & Windows \\
Software & Krpano (application) \& mySQL (database) & Bult-in web browser \& NGRAIN software \\
Network & Ethernet link & Ethernet/WiFi access \\
\hline
\end{tabular}

\subsection{Case Study}

After the system setup stage, case studies related to construction hazard topics are developed for the iAPR prototype in order to evaluate the learning framework and the proposed system. A virtual high-rise building jobsite, which includes fourteen floors and a basement, was chosen for the construction hazard investigation. According to Occupational Health and Safety Administration (OSHA) statistic, "Fatal Four" [54] (falls, struck by object, electrocutions, and caught-in/between accidents) constitute the highest rate of construction accidents in a year, therefore hazard case studies related to "Fatal Four" are chosen for the iAPR trial system, which are summarized in Table 2.

Table 2. Case studies for construction hazard investigation.

\begin{tabular}{|c|c|c|c|}
\hline No. & Fatal Four & Potential Hazards & Virtual Scenario \\
\hline 1 & Falls & Fall from mobile scaffold & 1st floor \\
\hline 2 & Falls & Fall from 2nd floor to ground floor due to lack of guardrails & 2nd floor \\
\hline 3 & Falls & $\begin{array}{l}\text { Falling from temporary ladder during installation of } \\
\text { ceiling panels }\end{array}$ & 3rd floor \\
\hline 4 & Falls & $\begin{array}{l}\text { Fall from stair due to lack of temporary handrails at the } \\
\text { edge of floor }\end{array}$ & 5 th floor \\
\hline 5 & Falls & $\begin{array}{l}\text { Fall from Boatswain's chair due to lack of an independent } \\
\text { lifeline }\end{array}$ & 11th floor \\
\hline 6 & Falls & $\begin{array}{l}\text { Fall into opening of stair at the 8th floor due to lack of } \\
\text { barriers }\end{array}$ & 8th floor \\
\hline 7 & Struck by object & Struck-by falling object due to lack of safety nets & Roof \\
\hline 8 & Struck by object & $\begin{array}{l}\text { Bricks falling from height on worker's head without safety } \\
\text { helmet }\end{array}$ & 7th floor \\
\hline 9 & Struck by object & $\begin{array}{l}\text { Metal pipes falling on worker's head during lifting } \\
\text { operation }\end{array}$ & 9th floor \\
\hline 10 & Electrocution & Electrocution when installing an air-conditioner & 10th floor \\
\hline 11 & Electrocution & Electrocution when using hand tool & Basement \\
\hline 12 & Caught-in/between & Worker is trapped during lift maintenance & 12th floor \\
\hline 13 & Caught-in/between & $\begin{array}{l}\text { Worker is caught between a truck and concrete due to } \\
\text { toppling over of precast concrete building unit }\end{array}$ & Ground floor \\
\hline
\end{tabular}

Firstly, the educators and learners log into the iAPR prototype through their own ID account, and then click on the HUM function (see Figure 2a) to start the hazard lesson. After that, the educator delivers online slides providing key hazards that often occur during high-rise building construction. With the educator's explanation and synthesis, the learners take part in "question and answer" activities with the educator and other learners until they thoroughly remember and understand all construction hazards in the lesson. Next, the learners log into the HRM function (see Figure 2b) to navigate a virtual high-rise building jobsite and investigate potential hazards. Following the educator's guidance, the learners inspect all hazard cases studies in a virtual construction site to acquire knowledge and skills. Finally, the learners play a testing simulation game using the SPM function (see Figure 2c) in order to assess their performance. 


\subsection{Evaluation Methodology}

In order to address the advantages and limitations of the proposed iAPR system, the evaluation scheme comprises of usability and effectiveness stages, as depicted in Figure 5.

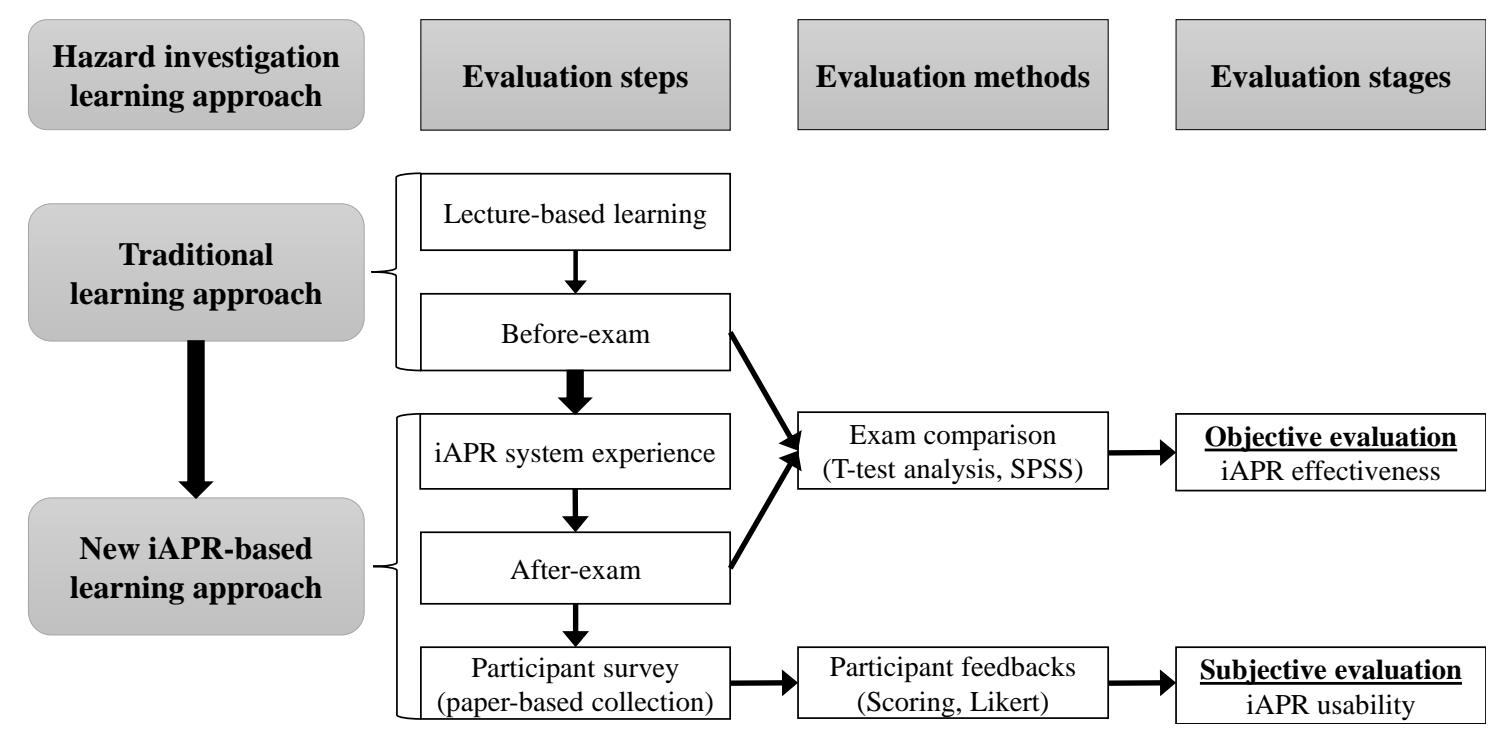

Figure 5. System evaluation scheme.

Following the evaluation steps, the educators disseminated the hazard investigation lessons to 40 learners through lecture-based learning. This is a traditional learning approach where educators provide lectures using a whiteboard and slides. After that, a before-exam was carried out to evaluate the learning outcome of learners before they used the iAPR platform in the subsequent steps. Thereafter, the learners were required to investigate and obtain hazard knowledge and skill using the iAPR platform. After new iAPR-based learning approach, these learners were examined by conducting an after-exam to evaluate the effectiveness of the proposed iAPR system.

Moreover, to validate the system usability, ten educators, ten construction professionals, and 40 students were asked to experience the iAPR platform. After that, all the participants took part in a survey through questionnaires and interviews, which evaluated the proposed system according to the following criteria [11,19,55,56]: (1) Sense of being in the construction jobsite; (2) Ease of hazard investigation and inspection; (3) Real-world visibility of construction jobsite; (4) Support of 3D object anatomization; (5) Interactiveness with virtual environment; and (6) Learning motivation and engagement of users. Finally, all their feedbacks were scored and analyzed using a five-point Likert scale, which range from 1 point for strongly disagree to 5 points for strongly agree.

\subsection{Evaluation Results}

Table 3 provides the average results of two exams, which were attempted by 40 four-year construction students before and after using the iAPR system for learning. To objectively compare the learning outcome of the learners, a paired sample T-test (called the dependent sample $t$-test) was developed to determine whether the mean difference between the two exams was statistically significant. The null hypothesis was that the mean difference between the two exam scores is equal, while the alternative hypothesis was that the mean difference between the two exam scores is not equal. The SPSS.20 statistics software was utilized to statistically analyze the before-exam and after-exam scores at the 5\% significance level. According to Table 3, the mean value and standard deviation are 76.250 and 4.770, respectively for the before-exam, while they are 80.125 and 4.001, respectively, for the after-exam. Since the Sig. (2-tailed) value of 0.001 (see Table 4) is less than the significance level of 0.05, the null hypothesis was rejected. Because of this, it is concluded that there is a statistically significant 
difference between the mean scores of the two exams. Meanwhile, the effectiveness evaluation results in Table 3 reveal that learners using the iAPR system for construction hazard investigation would have higher scores (80.125) than those who do not utilize the proposed platform for learning (76.250). Therefore, it proves that the proposed iAPR system can assist learners in improving hazard investigation knowledge and skill.

Table 3. Effectiveness evaluation result.

\begin{tabular}{cccc}
\hline & N & Mean & Standard Deviation \\
\hline Before-exam & 40 & 76.250 & 4.770 \\
After-exam & 40 & 80.125 & 4.001 \\
\hline
\end{tabular}

Table 4. Paired Samples Test.

\begin{tabular}{|c|c|c|c|c|c|c|c|c|}
\hline & \multicolumn{5}{|c|}{ Paired Differences } & \multirow{3}{*}{$\mathbf{t}$} & \multirow{3}{*}{ df } & \multirow{3}{*}{ Sig. (2-Tailed) } \\
\hline & \multirow[t]{2}{*}{ Mean } & \multirow{2}{*}{$\begin{array}{l}\text { Std. } \\
\text { Deviation }\end{array}$} & \multirow{2}{*}{$\begin{array}{l}\text { Std. Error } \\
\text { Mean }\end{array}$} & \multicolumn{2}{|c|}{$\begin{array}{l}95 \% \text { Confidence Interval } \\
\text { of the Difference }\end{array}$} & & & \\
\hline & & & & Lower & Upper & & & \\
\hline $\begin{array}{l}\text { Pair: } \\
\text { Before-After } \\
\text { exams }\end{array}$ & -3.87500 & 5.48746 & 0.86764 & -5.62997 & -2.12003 & -4.466 & 39 & 0.000 \\
\hline
\end{tabular}

Figure 6 depicts the results of iAPR usability evaluation, focusing on the six aforementioned criteria. The interviews and questionnaires related to the criteria for usability evaluation were conducted with all participants including the ten educators, ten construction managers, and 40 learners right after they experienced the iAPR prototype. For the first question "your sense of being in the construction site", which was adopted from [56], all the participants totally agreed that they had a good sense of being in a real construction workplace. Moreover, the users stated that the iAPR design is intuitive so that they could easily investigate and inspect the potential hazards by using mouses (for PCs, laptops) or their own fingers (for smart devices). The functions and tools designed in the iAPR prototype are user-friendly and similar to popular applications in various operating environments such as PCs and laptops as well as smart devices (e.g., ipad, tablets); therefore, it is easy for users to interact with the virtual environment. Regarding real-world visibility, the learners emphasized the advantage of the $360 \mathrm{VP}$ technology, which could present the virtual jobsite more realistically than other 3D-VR technologies. They also pointed out that the support of 3D object anatomization function in the iAPR is very necessary to assist learners in proposing prevention methods, which are very important for hazard elimination. Finally, the participants agreed that the iAPR motivates and engages them in learning construction hazard investigation and inspection. 


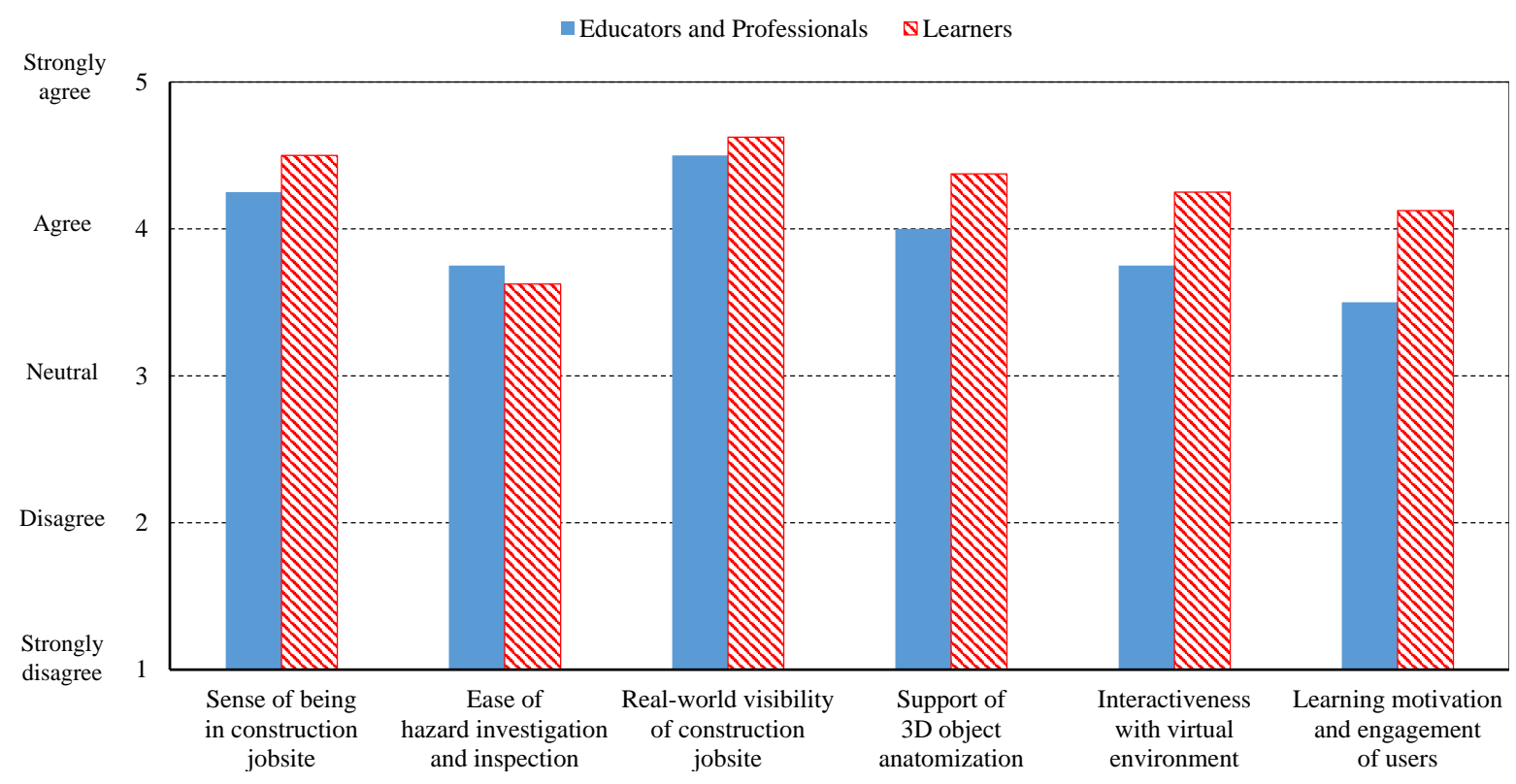

Figure 6. Usability evaluation.

\section{Conclusions}

Hazard investigation education is very important for equipping learners with adequate knowledge and skills to reduce potential hazards at construction jobsites. Therefore, research efforts have studied and adapted the state-of-the-art technologies such as 360VP and 3D-VR to promote construction hazard education in recent years. Despite the significant benefits of providing an engaging and immersive learning environment, 360VP does not have 3D object anatomization tools to support learning, while the 3D-VR limitation is a lack of providing a real-world environment. Meanwhile, it is a fact that a lack of research integrates these technologies in order to eliminate limitations and maximize advantages for enhancing learning outcomes. Thus, this research objective focuses on developing a construction hazard investigation system entitled iAPR, which integrates 360VP and 3D-VR technologies by leveraging 3D object anatomization on a 360VP platform. The proposed iAPR system consists of three key learning modules, namely HUM, HRM, and SPM, which adopt the revised Bloom's taxonomy theory to improve hazard education. The iAPR prototype were developed, and the usability of the system was evaluated by users including educators, construction professionals, and learners. Moreover, a comparison between before-exam and after-exam results is carried out objectively in order to evaluate the effectiveness of the iAPR platform. Preliminary findings prove that the iAPR has significant pedagogic methods to improve the learner's construction hazard investigation knowledge and skills, which improves safety performance.

Despite the proposed advantages of the iAPR system, future works need to further investigate the following perspectives:

- Regarding an adaptability and reality, an extended study of deploying the iAPR system on various wearable devices should to be conducted, e.g., head-mounted-displays, Microsoft Hololens, Google glass, etc.

- From usability and popularity perspectives, cost efficiency should be considered in terms of initial investigation, and maintenance as well as human labor.

- In application and utilization points of view, it is necessary to conduct an in-depth investigation of how much improvement in learning outcome the learners would obtain in different types of construction such as bridges, tunnels, damps, etc.

- In terms of systematical implementation and elasticity, since this research proposes and validates the iAPR system in a prototype, a full-scale system of iAPR should be deployed in order to comprehensively validate the system performance for a large number of learners. 
Author Contributions: Conceptualization, H.C.P. and A.-T.P.-H.; Data curation, H.C.P. and A.-T.P.-H.; Methodology, H.C.P.; Software, N.-N.D., S.C. and A.-T.P.-H.; Supervision, H.C.P. and A.-T.P.-H.; Validation, H.C.P., P.T.N. and A.-T.P.-H.; Writing—original draft, H.C.P., N.-N.D. and A.-T.P.-H.; Writing—review \& editing, S.C.

Conflicts of Interest: The authors declare no conflict of interest.

\section{References}

1. Park, C.S.; Kim, H.J. A framework for construction safety management and visualization system. Autom. Constr 2013, 33, 95-103. [CrossRef]

2. Zaira, M.M.; Hadikusumo, B.H. Structural equation model of integrated safety intervention practices affecting the safety behaviour of workers in the construction industry. Saf. Sci. 2017, 98, 124-135. [CrossRef]

3. Le, Q.T.; Lee, D.Y.; Park, C.S. A social network system for sharing construction safety and health knowledge. Autom. Constr. 2014, 46, 30-37. [CrossRef]

4. Raheem, A.A.; Hinze, J.W. Disparity between construction safety standards: A global analysis. Saf. Sci. 2014, 70, 276-287. [CrossRef]

5. Le, Q.T.; Pedro, A.; Park, C.S. A social virtual reality based construction safety education system for experiential learning. J. Intell. Robot. Syst. 2015, 79, 487-506. [CrossRef]

6. Wybo, J.L.; Van Wassenhove, W. Preparing graduate students to be HSE professionals. Saf. Sci. 2016, 81, 25-34. [CrossRef]

7. Arezes, P.M.; Swuste, P. Occupational health and safety post-graduation courses in Europe: A general overview. Saf. Sci. 2012, 50, 433-442. [CrossRef]

8. Wang, P.; Wu, P.; Wang, J.; Chi, H.L.; Wang, X. A critical review of the use of virtual reality in construction engineering education and training. Int. J. Environ. Res. Public Health 2018, 15, 1204. [CrossRef]

9. Le, Q.T.; Pedro, A.; Lim, C.; Park, H.; Park, C.; Kim, H. A framework for using mobile based virtual reality and augmented reality for experiential construction safety education. Int. J. Eng. Educ. 2015, 31, 713-725.

10. Gheisari, M.; Foroughi Sabzevar, M.; Chen, P.; Irizzary, J. Integrating bim and panorama to create a semi-augmented-reality experience of a construction site. Int. J. Constr. Educ. Res. 2016, 12, 303-316. [CrossRef]

11. Le, Q.T.; Pedro, A.; Pham, H.C.; Park, C.S. A Virtual World Based Construction Defect Game for Interactive and Experiential Learning. Int. J. Eng. Educ. 2016, 32, 457-467.

12. Pham, H.C.; Pedro, A.; Le, Q.T.; Lee, D.Y.; Park, C.S. Interactive safety education using building anatomy modelling. Univers. Access Inf. 2017. [CrossRef]

13. McLachlan, J.C.; Bligh, J.; Bradley, P.; Searle, J. Teaching anatomy without cadavers. Med. Educ. 2004, 38, 418-424. [CrossRef] [PubMed]

14. Petersson, H.; Sinkvist, D.; Wang, C.; Smedby, Ö. Web-based interactive 3D visualization as a tool for improved anatomy learning. Anat. Sci. Educ. 2009, 2, 61-68. [CrossRef] [PubMed]

15. Sugand, K.; Abrahams, P.; Khurana, A. The anatomy of anatomy: A review for its modernization. Anat. Sci. Educ. 2010, 3, 83-93. [CrossRef] [PubMed]

16. Eiris Pereira, R.; Gheisari, M. Site Visit Application in Construction Education: A Descriptive Study of Faculty Members. Int. J. Constr. Educ. Res. 2017. [CrossRef]

17. Eiris, R.; Gheisari, M.; Esmaeili, B. PARS: Using augmented 360-degree panoramas of reality for construction safety training. Int. J. Environ. Res. Public Health 2018, 15, 2452. [CrossRef]

18. Pham, H.C.; Dao, N.N.; Pedro, A.; Le, Q.T.; Hussain, R.; Cho, S.; Park, C.S. Virtual Field Trip for Mobile Construction Safety Education using 360-degree Panoramic Virtual Reality. Int. J. Eng. Educ. 2018, 34, 1174-1191.

19. Pham, H.C.; Dao, N.N.; Kim, J.U.; Cho, S.; Park, C.S. Energy-Efficient Learning System Using Web-Based Panoramic Virtual Photoreality for Interactive Construction Safety Education. Sustainability 2018, 10, 2262. [CrossRef]

20. Jeelani, I.; Albert, A.; Azevedo, R.; Jaselskis, E.J. Development and testing of a personalized hazard-recognition training intervention. J. Constr. Eng. Manag. 2016, 143, 04016120. [CrossRef]

21. Bloom, B.S. Taxonomy of Educational Objectives: The Classification of Educational Goals: Cognitive Domain; Longman: London, UK, 1956. 
22. Kratwohl, D.R.; Bloom, B.S.; Masia, B.B. Taxonomy of Educational Objectives, the Classification of Educational Goals-Handbook II: Affective Domain; McKay: New York, NY, USA, 1964.

23. Simpson, E.J. The Classification of Educational Objectives, Psychomotor Domain; Department of Health, Education, and Welfare, Office of Edcn.: Boston, MA, USA, 1974.

24. Dave, R. Developing and Writing Behavioural Objectives; Educational Innovators Press: Tucson, AZ, USA, 1975.

25. Harrow, A.J. A Taxonomy of the Psychomotor Domain: A Guide for Developing Behavioral Objectives; Addison-Wesley Longman Ltd.: Boston, MA, USA, 1972.

26. Anderson, L.W.; Krathwohl, D.R.; Airasian, P.W.; Cruikshank, K.A.; Mayer, R.E.; Pintrich, P.R.; Raths, J.; Wittrock, M.C. A Taxonomy for Learning, Teaching, and Assessing: A Revision of Bloom's Taxonomy of Educational Objectives, Abridged Edition; Longman: White Plains, NY, USA, 2001.

27. Murtonen, M.; Gruber, H.; Lehtinen, E. The return of behaviourist epistemology: A review of learning outcomes studies. Educ. Res. Rev. 2017, 22, 114-128. [CrossRef]

28. Thambyah, A. On the design of learning outcomes for the undergraduate engineer's final year project. Eng. J. Eng. Educ. 2011, 36, 35-46. [CrossRef]

29. Sharunova, A.; Butt, M.; Kresta, S.; Carey, J.; Wyard-Scott, L.; Adeeb, S.; Blessing, L.; Qureshi, A. Cognition and transdisciplinary design: An educational framework for undergraduate engineering design curriculum development. Eng. Educ. 2017, 16, 27. [CrossRef]

30. Agarwal, P.K. Retrieval practice \& Bloom's taxonomy: Do students need fact knowledge before higher order learning? J. Educ. Psychol. 2018. [CrossRef]

31. Hew, K.F.; Cheung, W.S. Use of Web 2.0 technologies in K-12 and higher education: The search for evidence-based practice. Educ. Res. Rev. 2013, 9, 47-64. [CrossRef]

32. Hussain, R.; Pedro, A.; Lee, D.Y.; Pham, H.C.; Park, C.S. Impact of safety training and interventions on training-transfer: targeting migrant construction workers. Int. J. Occup. Saf. Ergon. 2018. [CrossRef]

33. Kaskutas, V.; Dale, A.M.; Lipscomb, H.; Gaal, J.; Fuchs, M.; Evanoff, B. Changes in fall prevention training for apprentice carpenters based on a comprehensive needs assessment. J. Saf. Res. 2010, 41, 221-227. [CrossRef]

34. Endroyo, B.; Yuwono, B.E.; Mardapi, D. Model of learning/training of Occupational Safety \& Health (OSH) based on industry in the construction industry. Procedia Eng. 2015, 125, 83-88. [CrossRef]

35. Pedro, A.; Pham, H.C.; Kim, J.U.; Park, C.S. Development and Evaluation of Context-based Assessment System for Visualization-Enhanced Construction Safety Education. Int. J. Occup. Saf. Ergon. 2018. [CrossRef]

36. Pham, H.C.; Le, Q.T.; Pedro, A.; Park, C.S. Visualization Based Building Anatomy Model for Construction Safety Education. In Proceedings of the The 6th International Conference on Construction Engineering and Project Management (ICCEPM), Busan, Korea, 11-14 October 2015; pp. 1-5.

37. Pedro, A.; Chien, P.H.; Park, C.S. Towards a Competency-based Vision for Construction Safety Education. iN IOP Conference Series: Earth and Environmental Science; IOP Publishing: London, UK, 2018; Volume 143, p. 012051.

38. Hadikusumo, B.; Rowlinson, S. Integration of virtually real construction model and design-for-safety-process database. Autom. Constr. 2002, 11, 501-509. [CrossRef]

39. Perlman, A.; Sacks, R.; Barak, R. Hazard recognition and risk perception in construction. Saf. Sci. 2014, 64, 22-31. [CrossRef]

40. Albert, A.; Hallowell, M.R.; Kleiner, B.; Chen, A.; Golparvar-Fard, M. Enhancing construction hazard recognition with high-fidelity augmented virtuality. J. Constr. Eng. Manag. 2014, 140, 04014024. [CrossRef]

41. Li, H.; Chan, G.; Skitmore, M. Multiuser virtual safety training system for tower crane dismantlement. J. Comput. Civ. Eng. 2012, 26, 638-647. [CrossRef]

42. Goulding, J.; Nadim, W.; Petridis, P.; Alshawi, M. Construction industry offsite production: A virtual reality interactive training environment prototype. Adv. Eng. Inf. 2012, 26, 103-116. [CrossRef]

43. Sacks, R.; Perlman, A.; Barak, R. Construction safety training using immersive virtual reality. Constr. Manag. Econ. 2013, 31, 1005-1017. [CrossRef]

44. Lin, K.Y.; Son, J.W.; Rojas, E.M. A pilot study of a 3D game environment for construction safety education. J. Inf. Technol. Constr. 2011, 16, 69-84.

45. Moore, H.F.; Eiris, R.; Gheisari, M.; Esmaeili, B. Hazard Identification Training Using 360-Degree Panorama vs. Virtual Reality Techniques: A Pilot Study. In Computing in Civil Engineering 2019: Visualization, Information Modeling, and Simulation; American Society of Civil Engineers Reston: Reston, VA, USA, 2019; pp. 55-62. 
46. Na, W.; Dao, N.N.; Kim, J.; Ryu, E.S.; Cho, S. Simulation and Measurement: Feasibility Study of Tactile Internet Applications for mmWave Virtual Reality (VR). ETRI J. 2019, in press.

47. Dao, N.N.; Lee, J.; Vu, D.N.; Paek, J.; Kim, J.; Cho, S.; Chung, K.S.; Keum, C. Adaptive resource balancing for serviceability maximization in fog radio access networks. IEEE Access 2017, 5, 14548-14559. [CrossRef]

48. Dao, N.N.; Sa'ad, U.; Vu, V.C.; Tran, Q.D.; Ryu, E.S.; Cho, S. A Softwarized Paradigm for Mobile Virtual Networks: Overcoming a Lack of Access Infrastructure. IEEE Veh. Technol. Mag. 2018, 13, 106-115. [CrossRef]

49. Krpano 1.19. Available online: https:/ / krpano.com/ (accessed on 24 March 2019).

50. mySQL. Available online: https:/ / dev.mysql.com/ (accessed on 24 March 2019).

51. Raspberry Pi 3 Model B. Available online: https:/ / www.raspberrypi.org/products/raspberry-pi-3-model-b/ (accessed on 24 March 2019).

52. NGRAIN 5.1.1. Available online: http:/ / ngrain.com (accessed on 24 March 2019).

53. Samsung Gear 360. Available online: https://www.samsung.com/global/galaxy/gear-360/ (accessed on 24 March 2019).

54. Occupational Health and Safety Administration, United States Department of Labor. Available online: https: / www.osha.gov/oshstats/ commonstats.html (accessed on 24 March 2019).

55. Virvou, M.; Katsionis, G. On the usability and likeability of virtual reality games for education: The case of VR-ENGAGE. Comput. Educ. 2008, 50, 154-178. [CrossRef]

56. Usoh, M.; Catena, E.; Arman, S.; Slater, M. Using presence questionnaires in reality. Presence Teleoperators Virtual Environ. 2000, 9, 497-503. [CrossRef]

(C) 2019 by the authors. Licensee MDPI, Basel, Switzerland. This article is an open access article distributed under the terms and conditions of the Creative Commons Attribution (CC BY) license (http:/ / creativecommons.org/licenses/by/4.0/). 